\title{
Effect of Initial Backfill Temperature on the Deformation Behavior of Early Age Cemented Paste Backfill That Contains Sodium Silicate
}

\author{
Aixiang Wu, ${ }^{1}$ Yong Wang, ${ }^{1,2}$ Bo Zhou, ${ }^{1}$ and Jiahua Shen ${ }^{3}$ \\ ${ }^{1}$ Key Laboratory of High-Efficient Mining and Safety of Metal Mines, Ministry of Education, University of Science and \\ Technology Beijing, Beijing 100083, China \\ ${ }^{2}$ State Key Laboratory of Advanced Metallurgy, University of Science and Technology Beijing, Beijing 100083, China \\ ${ }^{3}$ Africa Mining PLC of China Nonferrous Metals Co., Ltd., P.O. Box 22592, Kitwe, Zambia \\ Correspondence should be addressed to Yong Wang; wangyong8551@126.com
}

Received 7 September 2015; Accepted 26 June 2016

Academic Editor: Peter Majewski

Copyright (C) 2016 Aixiang Wu et al. This is an open access article distributed under the Creative Commons Attribution License, which permits unrestricted use, distribution, and reproduction in any medium, provided the original work is properly cited.

Enhancing the knowledge on the deformation behavior of cemented paste backfill (CPB) in terms of stress-strain relations and modulus of elasticity is significant for economic and safety reasons. In this paper, the effect of the initial backfill temperature on the CPB's stress-strain behavior and modulus of elasticity is investigated. Results show that the stress-strain relationship and the modulus of elasticity behavior of CPB are significantly affected by the curing time and initial temperature of CPB. Additionally, the relationship between the modulus of elasticity and unconfined compressive strength (UCS) and the degree of hydration was evaluated and discussed. The increase of UCS and hydration degree leads to an increase in the modulus of elasticity, which is not significantly affected by the initial temperature.

\section{Introduction}

Cemented paste backfill (CPB) is a cementitious material that is used extensively in underground mines worldwide. It is an engineering mixture of dewatered tailings generated during mineral processing and contains a hydraulic binder (e.g., cement) and water [1]. The main benefits of $\mathrm{CPB}$ technology are the reduced amount of waste disposal and the significant environmental and economic benefits for mines. Many underground mines consider CPB in their backfill system selection due to its proven, cost-effective, and highquality performance $[2,3]$.

Mechanical stability is an important quality criterion for hardened CPB [4]. Since the backfilled stope and the roof must be self-supporting or stable, the adjacent stopes are extracted to ensure the safety of workers. Information about the deformation behavior of CPB under compression (CPB structures are mostly subjected to compression in their service life) is essential for the rigorous evaluation of its mechanical stability. The mechanical response of a $\mathrm{CPB}$ material under load is largely controlled by the stress-strain relationship of the constituent materials and the magnitude of stress [4]. Therefore, understanding the stress-strain behavior of $\mathrm{CPB}$ in compression is critical for the design of safe $\mathrm{CPB}$ structures. The modulus of elasticity $(E)$ is another important parameter for the deformation behavior assessment of $\mathrm{CPB}$. Many studies have investigated the relationship between $E$ and compressive strength of concrete [5]. However, only limited studies have been done on CPB [4].

Despite the progress made in the past few years in understanding the deformation behavior of $\mathrm{CPB}$, some major technological and fundamental aspects are still not well understood. For instance, our understanding of the effect of initial $\mathrm{CPB}$ temperature on its deformation behavior is limited. Solid knowledge of CPB deformation behavior under various thermal loading conditions is important for the safe and economical design of CPB structures. CPBs can be subjected to a variety of thermal loading conditions. 
TABLE 1: Characteristics of the binders (PCI and Slag).

\begin{tabular}{lcccccccc}
\hline Type of binder & $\mathrm{MgO}(\%)$ & $\mathrm{CaO}(\%)$ & $\mathrm{SiO}_{2}(\%)$ & $\mathrm{Al}_{2} \mathrm{O}_{3}(\%)$ & $\mathrm{Fe}_{2} \mathrm{O}_{3}(\%)$ & $\mathrm{SO}_{3}(\%)$ & Relative density & Specific surface $\left(\mathrm{m}^{2} / \mathrm{g}\right)$ \\
\hline PCI & 2.65 & 62.82 & 18.03 & 4.53 & 2.7 & 3.82 & 3.1 & 1.3 \\
Slag & 10.98 & 41.14 & 34.23 & 9.54 & - & 3.87 & 3.3 & - \\
\hline
\end{tabular}

TABLE 2: Physical characteristics of STs.

\begin{tabular}{lccccccc}
\hline Element & $G_{s}$ & $D_{10}(\mu \mathrm{m})$ & $D_{30}(\mu \mathrm{m})$ & $D_{50}(\mu \mathrm{m})$ & $D_{60}(\mu \mathrm{m})$ & $C_{u}$ & $C_{c}$ \\
\hline ST & 2.7 & 1.9 & 9 & 22.5 & 31.5 & 16.2 & 1.3 \\
\hline
\end{tabular}

These conditions depend on several parameters, such as mine depth, heat emitted by the binder hydration, initial temperature of the CPB mix components, and mine geographical location [6]. All of the aforementioned heat sources can lead to different initial backfill temperatures once the CPB is placed in the voids.

To date, no study has focused on the effect of initial temperature on the deformation properties of $\mathrm{CPB}$. Hence, this research aims to understand the effect of various initial backfill temperatures on the deformation behavior of CPB at early ages (up to 28 days) by conducting experimental tests.

\section{Materials and Methods}

2.1. Materials Used. The materials include two types of binders, artificial silica tailings, soluble sodium silicate, and mixing water.

2.1.1. Binders and Water. Portland cement type I (PCI) and blast furnace slag (Slag) were employed as binders. These materials are the most commonly used binders for the CPB operations of mines in eastern Canada. The mixing ratio of these binders was 50/50. Table 1 presents the physical and chemical properties of both PCI and Slag.

Tap water was employed as mixing water for the binders and tailings blending.

2.1.2. Silica Tailings. Silica tailings (STs) are a type of artificial tailings that contains $99.8 \% \mathrm{SiO}_{2}$. The use of artificial tailing enables an accurate control of the mineralogical and chemical composition of the tailings, thereby minimizing the level of uncertainties. STs also show a grain size distribution that is similar to the average particle size distribution of nine Canadian hard rock mines (Figure 1). STs can be classified as medium tailings because they have approximately 45 mass percent of fine particles $(<20 \mu \mathrm{m})$. Table 2 shows the physical characteristics of STs.

2.1.3. Sodium Silicate. Soluble sodium silicates, which are also referred to as water soluble glasses, are polymer liquids with the properties of clearness, colorlessness, and viscidity. In this study, soluble sodium silicate was used as an admixture for the CPB preparation. A commercial sodium silicate solution (type $\mathrm{N}$ ) with a ratio of $\mathrm{SiO}_{2}$ to $\mathrm{Na}_{2} \mathrm{O}$ of $3: 2$ was used. Sodium silicate was added as a liquid form; its properties are given in Table 3.
TABlE 3: Properties of sodium silicate (provided by National Silicates Ltd.).

\begin{tabular}{lc}
\hline Properties & Values \\
\hline $\mathrm{Na}_{2} \mathrm{O}$ wt.\% & 8.9 \\
$\mathrm{SiO}_{2}$ wt.\% & 28.66 \\
Weight ratio, wt.\% $\mathrm{SiO}_{2} /$ wt. $\% \mathrm{Na}_{2} \mathrm{O}$ & 3.22 \\
Specific gravity $\left(20^{\circ} \mathrm{C}\right)$ & 1.39 \\
Solids wt.\% & 37.56 \\
\hline
\end{tabular}

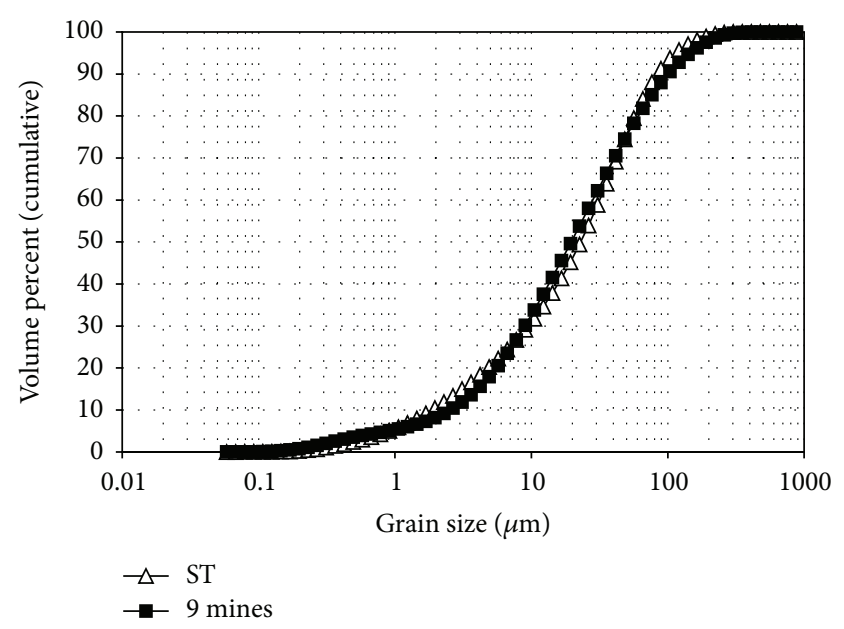

FIGURE 1: Grain size distribution of STs and the average distribution of tailing grain size from nine Canadian mines.

2.2. Specimen Preparation, Mix Proportions, and Curing. The CPB specimens were prepared with constant binder content (4.5\% mass), binder mass ratio (PCI/Slag: 50/50), water/cement ratio (7.6), sodium silicate content ( $0.4 \%$ mass), and STs. The components of the backfill (STs, cement, slag, and water) were stored in a temperature-controlled chamber to obtain the desired initial temperatures $(2,20,35$, and $\left.50^{\circ} \mathrm{C}\right)$. Thereafter, the backfill mixtures of tailings, binders, sodium silicate, and water were mixed by a Eurodib B20F mixer (approximately 7 minutes) until a homogeneous paste was obtained. Slump of the CPB mixtures was measured as $18 \mathrm{~cm}$ (the most commonly used slump value in Canadian CPB operations), using the ASTM C143 (2010) method. The resulting $\mathrm{CPB}$ mixtures with desired initial temperatures $\left(2,20,35\right.$, and $\left.50^{\circ} \mathrm{C}\right)$ were poured into thermally insulated 


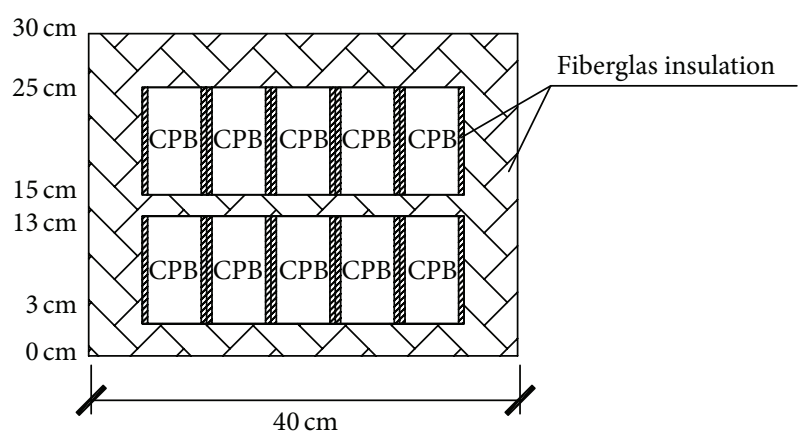

(a)

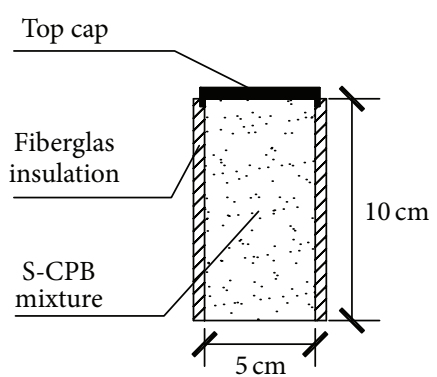

(b)

Figure 2: Schematic of the experimental curing setup: (a) location of cylinders in the insulation box and (b) illustration of the thermal insulating cylinder.

cylinders with diameters of $5 \mathrm{~cm}$ and heights of $10 \mathrm{~cm}$, respectively. The specimens in the cylinders were then sealed to avoid water evaporation. Finally, those thermally insulated cylinders with the same initial temperatures were placed into a thermal insulated and sealed box $(40 \mathrm{~cm} \times 30 \mathrm{~cm} \times 30 \mathrm{~cm})$ (Figure 2) to cure. Thus, a total of four insulation boxes were employed for the curing phase. These prepared insulation boxes with different initial temperature specimens were cured at room temperature for $0.25,3,7$, and 28 days. The purpose of the insulation was to reduce or slow down heat exchange between the CPB and surroundings because the CPB in the field is generally surrounded by the rock mass, which cannot transfer heat quickly.

2.3. Mechanical Tests of Specimens. Once the required curing ages $(0.25,3,7$, and 28 days) were achieved, the specimens were removed from the cylinders immediately. Unconfined compressive strength (UCS) tests were performed on these samples. A computer-controlled MTS 10/GL mechanical press with capacity of $50 \mathrm{kN}$ was employed for the specimen UCS test as per standard of ASTM C-39. A deformation rate of $0.8 \mathrm{~mm} / \mathrm{min}$ was employed during the test. Each test was conducted at least three times to make sure of the repeatability of the results.

In addition to the UCS test, the porosity was also performed on the CPB samples as per standard of ASTM D7263 (2009). Once the UCS test was finished, the broken CPBs were collected and measured with the mass of $m_{T}$. These CPB samples were put into the oven drying about 24 hours at the temperature of $95^{\circ} \mathrm{C}$ and measured with the mass of $m_{H}$ after being dried. The water content and dry density of CPB can be calculated using (1) and (2), respectively:

$$
\begin{aligned}
w & =\frac{m_{T}-m_{H}}{m_{H}}, \\
\rho_{d} & =\frac{100 \rho}{100+w},
\end{aligned}
$$

where $w$ is water content of $\mathrm{CPB}, \rho_{d}$ is dry density of $\mathrm{CPB}, \rho$ is density of $\mathrm{CPB}, m_{T}$ is the mass of $\mathrm{CPB}$ before drying, and $m_{H}$ is the mass of CPB after drying. It should be noted that the density $(\rho)$ of $\mathrm{CPB}$ indicated that mass of CPB divides the volume occupied. In the current study, these mass and volume referred to the cylinder volume and CPB mass inside the cylinder before UCS test. The porosity $n$ of CPB can be obtained based on the dry density and particle density as shown in the following equation:

$$
n=\frac{\rho_{s}-\rho_{d}}{\rho_{s}}
$$

\section{Results and Discussion}

3.1. Effect of Initial Temperature on the Stress-Strain Behavior of $C P B$. UCS tests were conducted on $32 \mathrm{CPB}$ specimens with various early curing ages. Figures $3(\mathrm{a})-3(\mathrm{~d})$ present a set of typical stress-strain curves from the results of UCS tests after curing periods of $0.25,3,7$, and 28 days. The shapes of the stress-strain curves are strongly affected by the initial temperature of CPB for a given different curing time. For most curing times, the peak strain value generally decreases with increasing initial temperature. The strain corresponding to the peak stress value is higher for the initial temperature of $2^{\circ} \mathrm{C}$ than for $20^{\circ} \mathrm{C}$ during the curing age of $0.25-28$ days. For the initial temperatures of $35^{\circ} \mathrm{C}$ and $50^{\circ} \mathrm{C}$, the strain values at the peak stress are almost the same but are smaller than those for $20^{\circ} \mathrm{C}$. This information can help elucidate the deformation behavior of CPB under various initial temperature conditions. When the initial temperature is high, the $\mathrm{CPB}$ shows a less plastic behavior than that at a low initial temperature. Furthermore, the level of stress generally decreases quickly with increasing initial temperatures in the postfailure region. The slopes of the stress-strain curves generally become steeper with increasing initial temperature.

Figures 4(a)-4(d) illustrate the effect of curing time on the CPB stress-strain relationship for different initial temperatures. All of these stress-strain profiles show the same varying pattern, thus indicating that the CPB stress-strain response is dependent on the curing time. For each initial temperature, the stress-strain response of $\mathrm{CPB}$ is more linear in the ascending branch with a longer curing time than with a shorter curing time. Simultaneously, the descending branch shows a sharp decrease with increasing curing time. The higher elastic behavior and decrease of the CPB stress-strain 


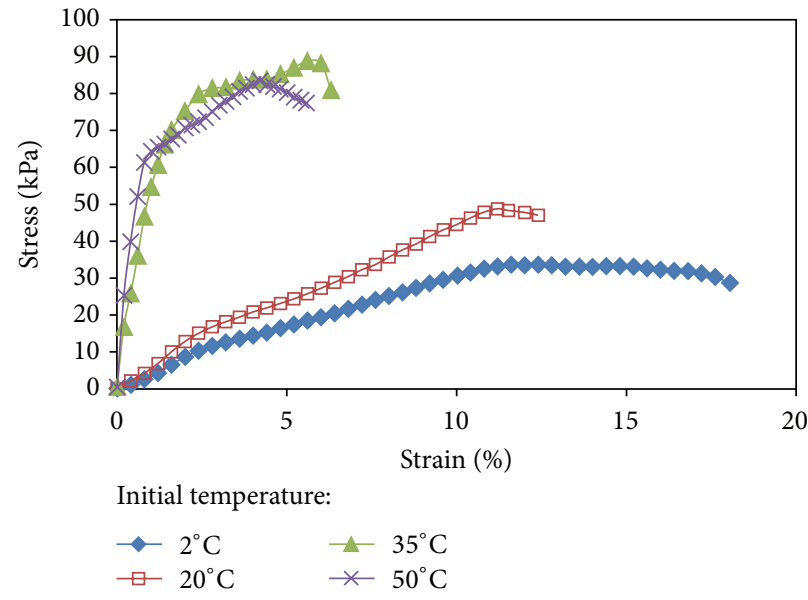

(a)

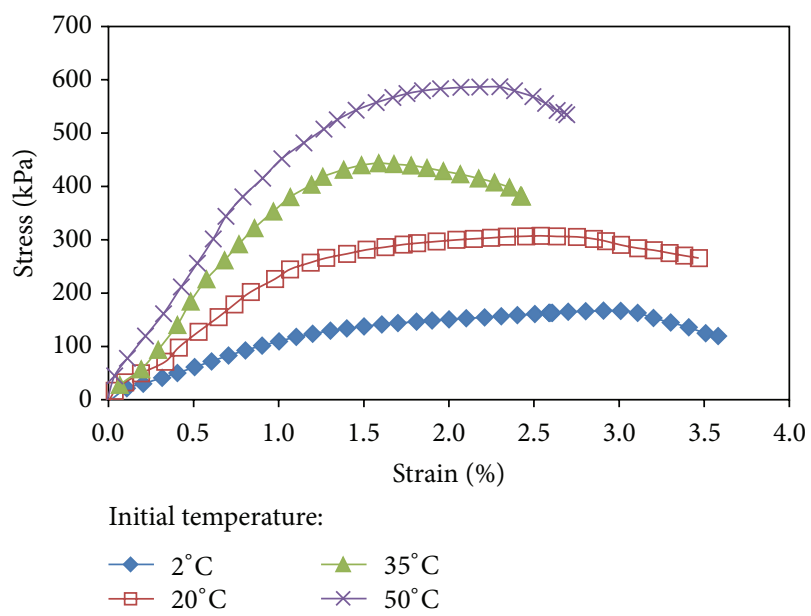

(c)

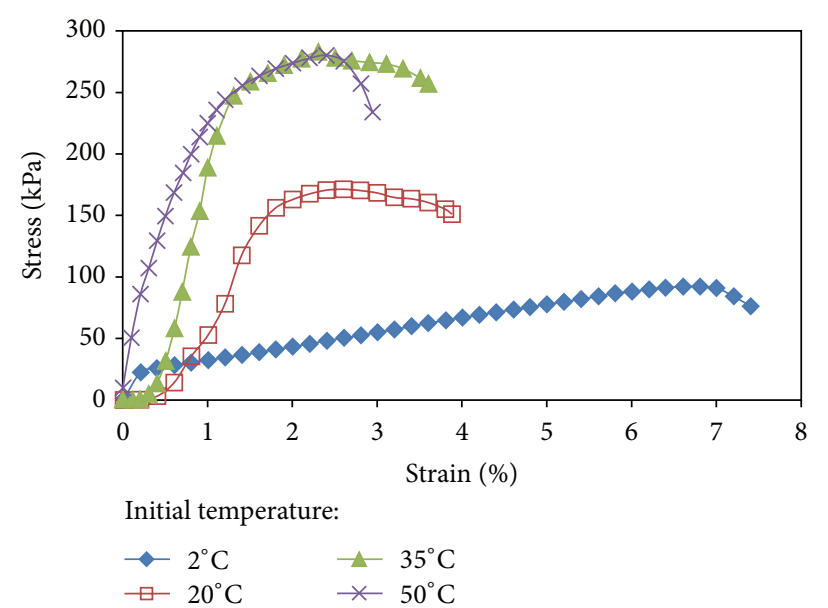

(b)

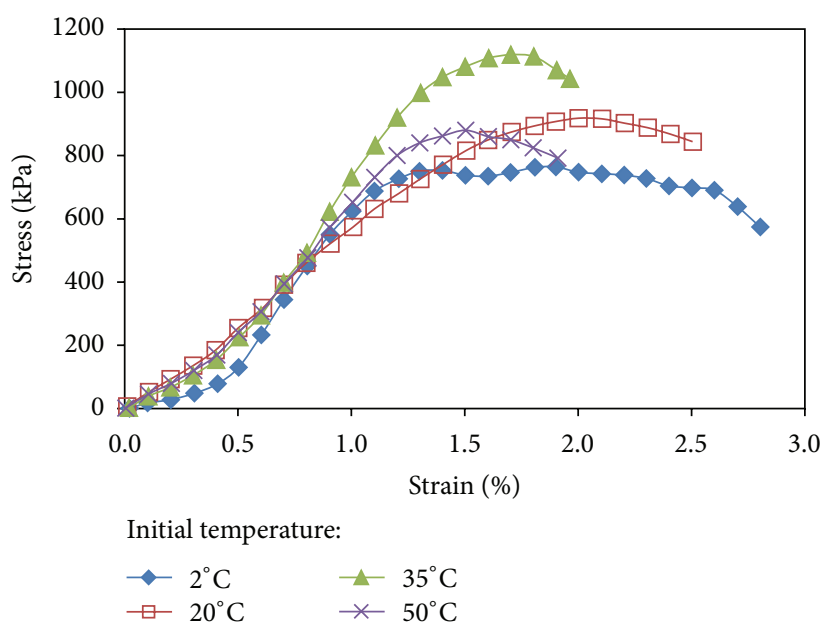

(d)

FIGURE 3: Effect of initial temperature on the stress-strain shape of CPB at different curing times: (a) 0.25 , (b) 3, (c) 7, and (d) 28 days.

curve can be due to the higher UCS at the advanced curing time. This phenomenon is due to the fact that small strain evolution needs a relatively bigger pressure load when the $\mathrm{CPB}$ samples have high strengths, thus leading to a linear stress-strain curve before reaching the peak stress. During this process, considerable energy is accumulated before the peak stress is achieved because the UCS is high, thus resulting in the rapid proliferation of cracks in the damage zone and the sharp decrease in stress [4].

3.2. Effect of Initial Temperature on the Modulus of Elasticity (E) of $C P B$. Figures 5(a) and 5(b) show the effect of initial temperature and curing time on the evolution of $E$, which was calculated from the stress-strain curves. Three methods are generally used for $E$ value determination, including tangent modulus $\left(E_{\max }\right)$, secant modulus $\left(E_{s}\right)$, and average modulus $\left(E_{50}\right)$, as per standard of ASTM D3148. $E_{50}$ is frequently employed in a geotechnical structure, since this $E_{50}$ referred to $50 \%$ of the failure stress and is in accord with typical operating situations of geotechnical structure during their service life [6]. Also, some other studies used $E_{50}$ as $E$ value of CPB $[1,4]$. Therefore, $E$ value of present research is obtained by $E_{50}$ calculation method. From Figure 5 , it can be observed that as the initial temperature increases or the curing age advances, $E$ value increases except for the initial temperature of $50^{\circ} \mathrm{C}$ at 28 days. This value is close to $E$ value of $20^{\circ} \mathrm{C}$ at 28 days. This result indicates that when the initial temperature increases to $50^{\circ} \mathrm{C}$ at curing age of 28 days, the $\mathrm{CPB}$ specimen becomes softer than that at $35^{\circ} \mathrm{C}$. This suggests that a coarser pore structure is present at $50^{\circ} \mathrm{C}$ than at $35^{\circ} \mathrm{C}$ after curing age of 28 days. This hypothesis is validated by the $\mathrm{CPB}$ porosity evolution results presented in Figure 6.

Figure 5(a) shows that $E$ values of CPB specimens with different initial temperatures all increase with increasing curing time. This result indicates that the $\mathrm{CPB}$ specimens tend to increase in stiffness with increasing curing time because of the progress of the cement hydration (Figure 9). Figure 5(b) illustrates the evolution of $E$ values with the initial temperatures at different curing stages. At a curing time of 0.25 days, the increase of $E$ value is insignificant for initial 

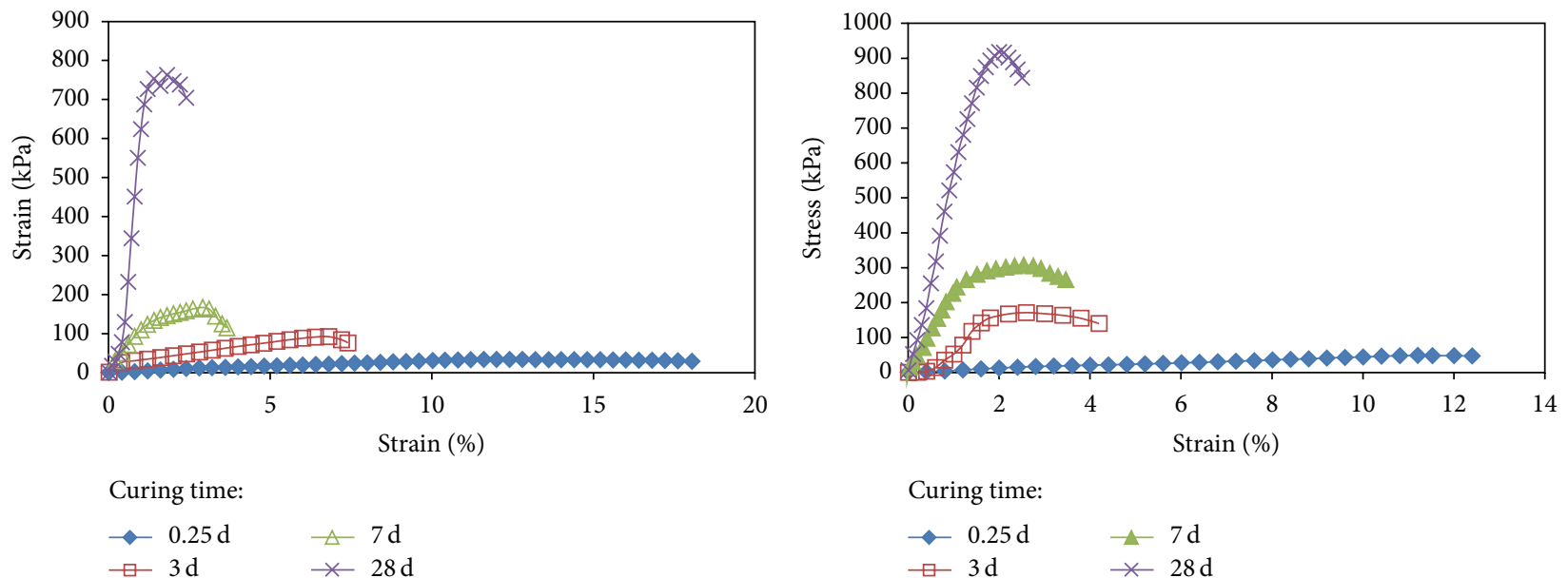

$$
\begin{array}{ll}
\text { Curing time: } & \\
-0.25 \mathrm{~d} & -7 \mathrm{~d} \\
\square-3 \mathrm{~d} & \times 28 \mathrm{~d}
\end{array}
$$

(a)

(b)

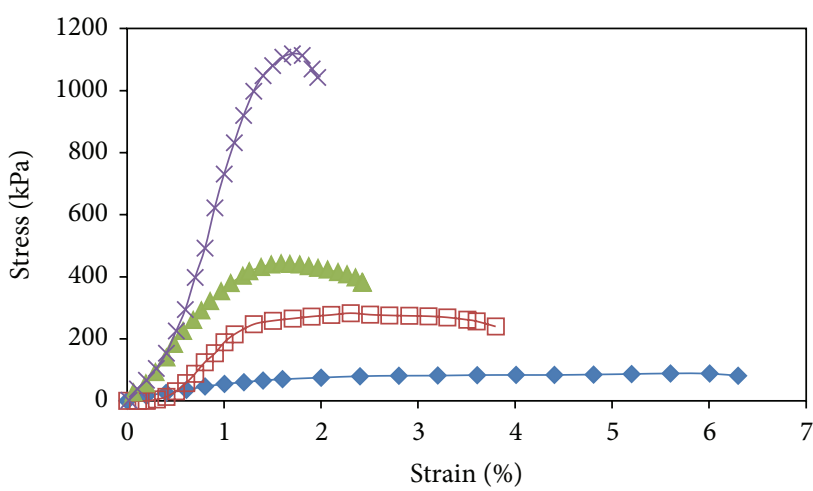

Curing time:

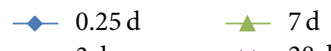

$\square 3 \mathrm{~d} \quad \times 28 \mathrm{~d}$

(c)

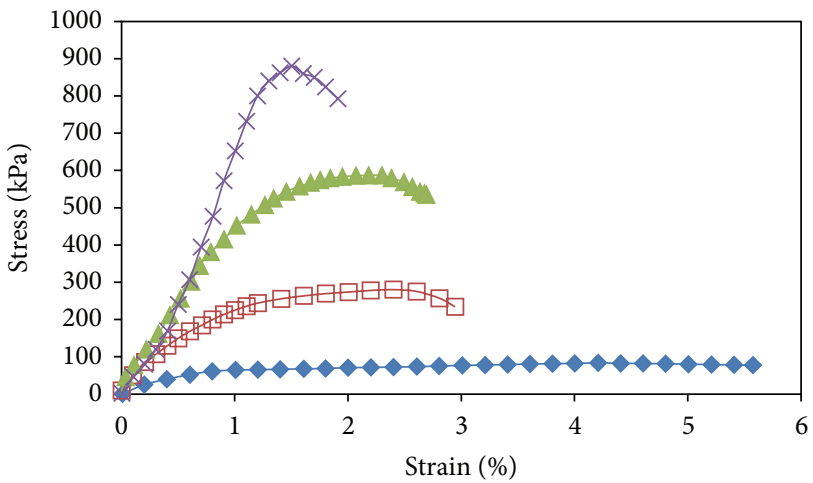

Curing time:

$\begin{array}{ll}\longrightarrow 0.25 \mathrm{~d} & -7 \mathrm{~d} \\ \square-3 \mathrm{~d} & \times 28 \mathrm{~d}\end{array}$

(d)

FIGURE 4: Effect of curing time on the stress-strain curve of CPB at different initial temperature: (a) 2, (b) 20 , (c) 35 , and (d) $50^{\circ} \mathrm{C}$.

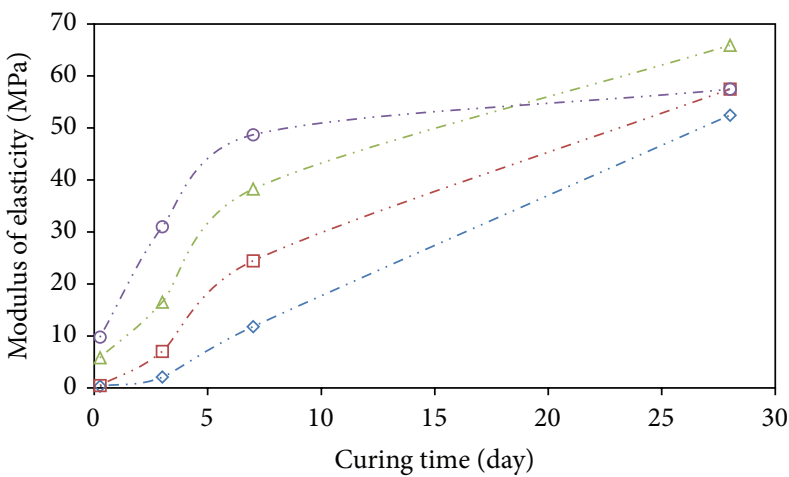

Initial temperature:

$\begin{array}{ll}-\diamond-2{ }^{\circ} \mathrm{C} & -\Delta-35^{\circ} \mathrm{C} \\ -\square-20^{\circ} \mathrm{C} & -0-50^{\circ} \mathrm{C}\end{array}$

(a)

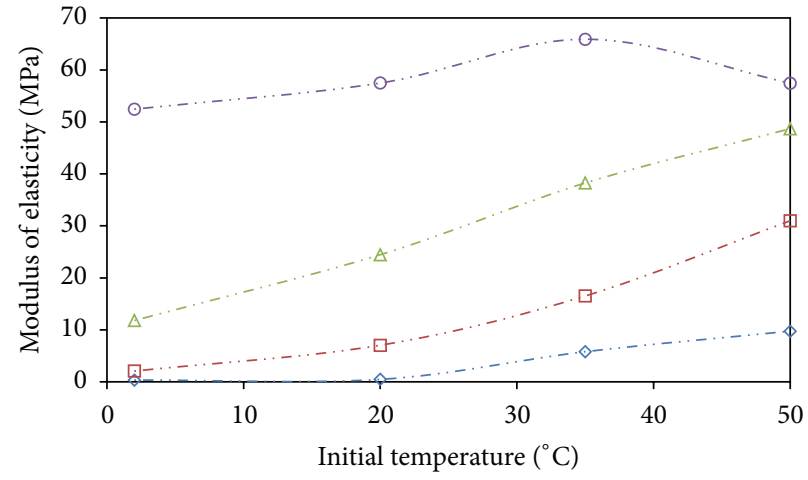

Curing time:

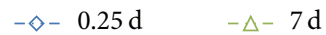

$-\boxminus-3 \mathrm{~d}-0-28 \mathrm{~d}$

(b)

FIGURE 5: Effect of initial temperature and curing time on the evolution of CPB E: (a) effect of curing time and (b) effect of initial temperature. 


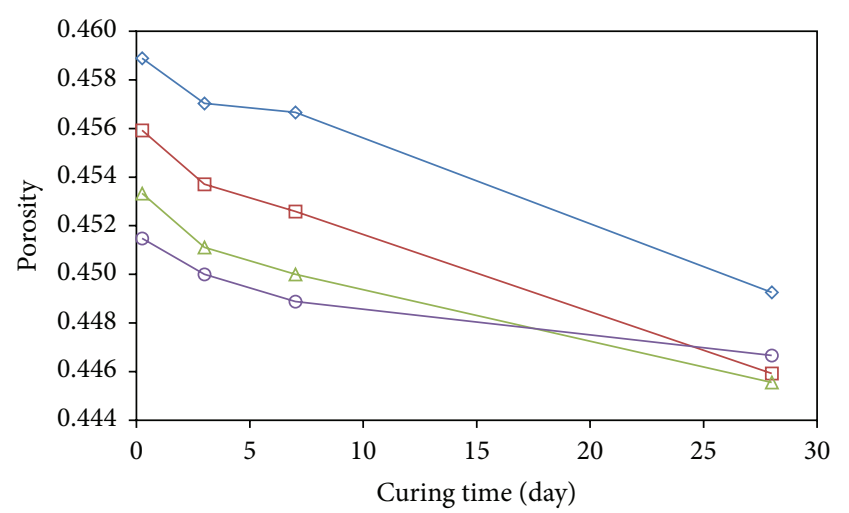

Initial temperature:

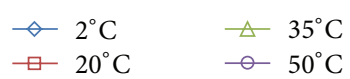

FIGURE 6: Effect of initial temperature on the evolution of porosity.

temperatures of $2^{\circ} \mathrm{C}$ and $20^{\circ} \mathrm{C}$ but a notable increase for initial temperatures higher than $20^{\circ} \mathrm{C}$ is shown. However, when the curing time advances to 3 and 7 days, a significant increase in $E$ value can be observed at all full initial temperatures used $\left(2^{\circ} \mathrm{C}-50^{\circ} \mathrm{C}\right)$. At curing time of 28 days, $E$ values increase slightly as the initial temperature increases from $2^{\circ} \mathrm{C}$ to $35^{\circ} \mathrm{C}$, while showing a slight reduction for an initial temperature of $50^{\circ} \mathrm{C}$. The aforementioned results denote that the effect of initial backfill temperature on $E$ value is most noticeable for curing times of 3 days to 7 days (early ages). This is an important stage for barricade opening in most mines. The effect of initial temperature on $E$ value is mainly due to the different hydration process of the binder at various initial temperatures. $E$ value has a significant relationship with the UCS of CPB samples, presented in Section 3.3.

3.3. Relationship between the Unconfined Compressive Strength and Modulus of Elasticity of CPB. Figures 7(a) and 7 (b) show the relationship between the compressive strength and $E$ of $\mathrm{CPB}$ samples with the different initial temperatures and curing ages in this investigation. Figure 7 (a) shows that, for each initial temperature, $E$ increases with increasing compressive strength. Furthermore, the differences between the curves for $\mathrm{CPB}$ with different initial temperatures are small. Therefore, the initial backfill temperature does not significantly affect the relationship between $E$ and UCS. This phenomenon is well known in concrete research and can be explained as follows. As the hydration products of CPB samples increase, the matrix and interface of cement paste increase in density and strength, thus increasing the similarity between the elastic properties of the cement paste matrix and tailings particles. Thus, high $E$ of $\mathrm{CPB}$ can be obtained [7-9]. Figure 7(b) presents the relationship between $E$ and UCS of the CPB specimens. $E$ tends to increase linearly with the square root of the UCS. This relationship between $E$ value and square root of the UCS can be expressed by the following equation:

$$
E=84.228 \sqrt{\mathrm{UCS}}-19.787
$$

where $E$ is CPB's modulus of elasticity in MPa and UCS is cylinder uniaxial compressive strength in $\mathrm{kPa}$.

Equation (4) indicates a strong relationship between $E$ and square root of the UCS. This relationship is in good agreement with the expression suggested by other studies that investigated the relationship between compressive strength and $E$ of concrete [10-12].

Figures 8(a) and 8(b) show the relationship between $E(t) / E(28)$ and UCS $(t) / \mathrm{UCS}(28)$ of CPB samples with different initial temperatures and curing times. As seen in Figure $8(\mathrm{a})$, the effect of initial temperature on the relationship between $E(t) / E(28)$ and $\operatorname{UCS}(t) / \mathrm{UCS}(28)$ is minor. The initial backfill temperature almost has no effect on the relationship of $E(t) / E(28)$ and $\operatorname{UCS}(t) / \operatorname{UCS}(28)$. Figure $8(\mathrm{~b})$ illustrates the trend line that best fits the scatter plot of $E(t) / E(28)$ and $\operatorname{UCS}(t) / \operatorname{UCS}(28)$, which is given as the following equation:

$$
\frac{E(t)}{E(28)}=1.0516\left[\frac{\mathrm{UCS}(t)}{\mathrm{UCS}(28)}\right],
$$

where $E(t)$ is the modulus of elasticity in MPa at the curing time of $t, E(28)$ is the modulus of elasticity in $\mathrm{MPa}$ at the time of 28 days, $\mathrm{UCS}(t)$ is the UCS in $\mathrm{kPa}$ at the curing time of $t$, and UCS(28) is UCS in the $\mathrm{kPa}$ at the age of 28 days. The slope and $R^{2}$ value of (5) are 1.0516 and 0.9517 , respectively, thus indicating that $E / E(28)$ is almost equal to UCS/UCS(28).

3.4. Evolution of the Modulus of Elasticity with Degree of Hydration of the Binder. This section will examine the evolution of $E$ with the degree of cement hydration. The following function expresses the degree of hydration [13]:

$$
\alpha\left(t_{e}\right)=\alpha_{u} \cdot \exp \left[-\left(\frac{\tau}{t_{e}}\right)^{\beta}\right],
$$

where $\alpha\left(t_{e}\right)$ is the degree of hydration at an equivalent age $t_{e}$, $\tau$ is the hydration time parameter $(\mathrm{h}), \beta$ is the hydration curve shape parameter, and $\alpha_{u}$ is the ultimate hydration degree.

The equivalent age can be expressed as the following equation [14]:

$$
t_{e}=\frac{\tau}{\tau_{T}} \cdot t
$$

where $\tau_{T}$ is the hydration time parameter at the temperature of cement-based materials and $t$ is the chronological age.

The value of the ultimate degree of hydration $\left(\alpha_{u}\right)$ is significantly affected by the water-binder ratio $(w / c)$ [15]. Equation (8), which is based on numerous experimental tests [16], is recommended as the expression for the ultimate degree of hydration for saturated cement-based materials:

$$
\alpha_{u}=\frac{1.031 \cdot w / c}{0.194+w / c}
$$

where $w / c$ is the ratio of water to binder.

The ultimate hydration degree is unaffected by the curing time [17]. The cement or binder generally cannot hydrate completely because of the low $w / c(0.2-0.6)$ commonly used 


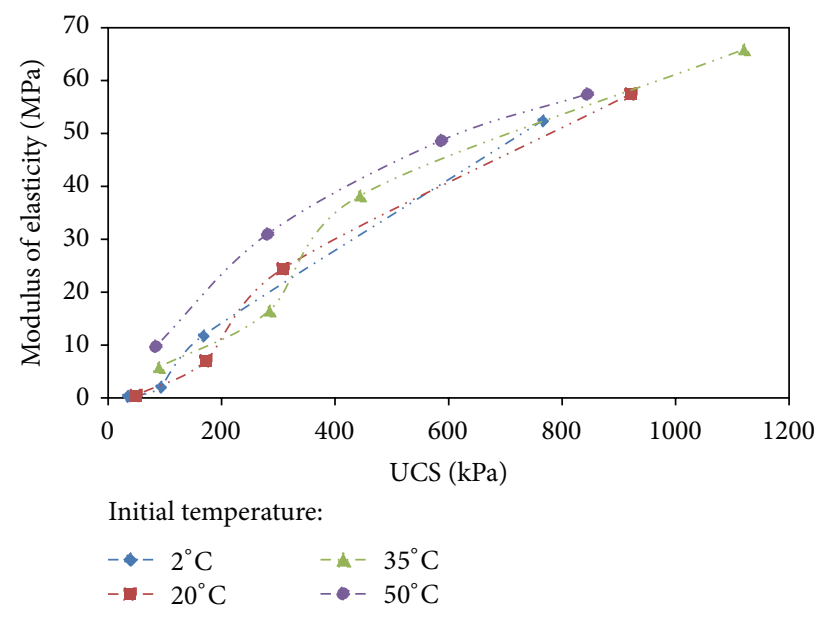

(a)

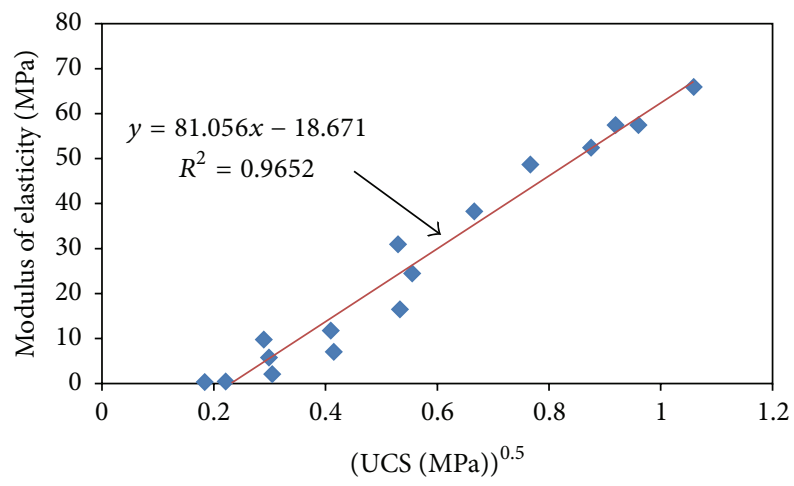

- Experimental results _ Fit curve

FIGURE 7: Relationship between $E$ and UCS: (a) evolution of $E$ with the various UCS at different initial temperature and (b) fit curve for $E$ and square root of the UCS.

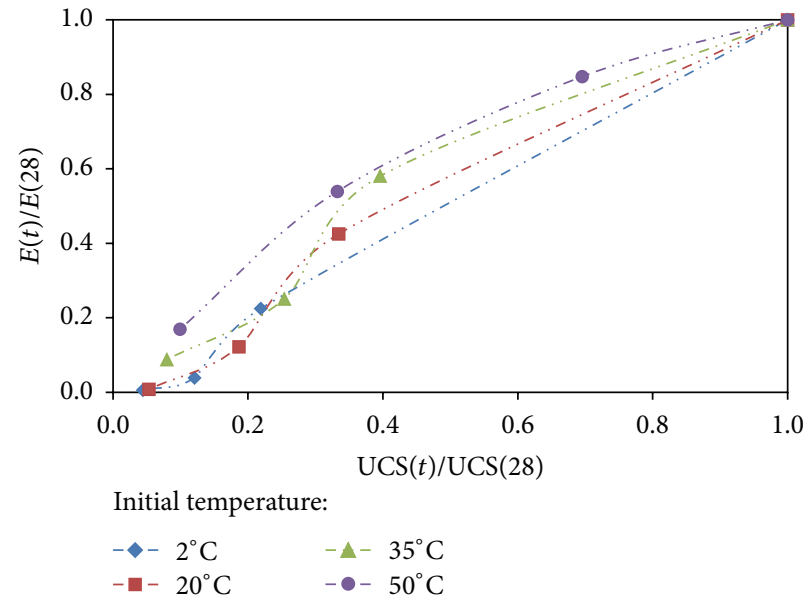

(a)

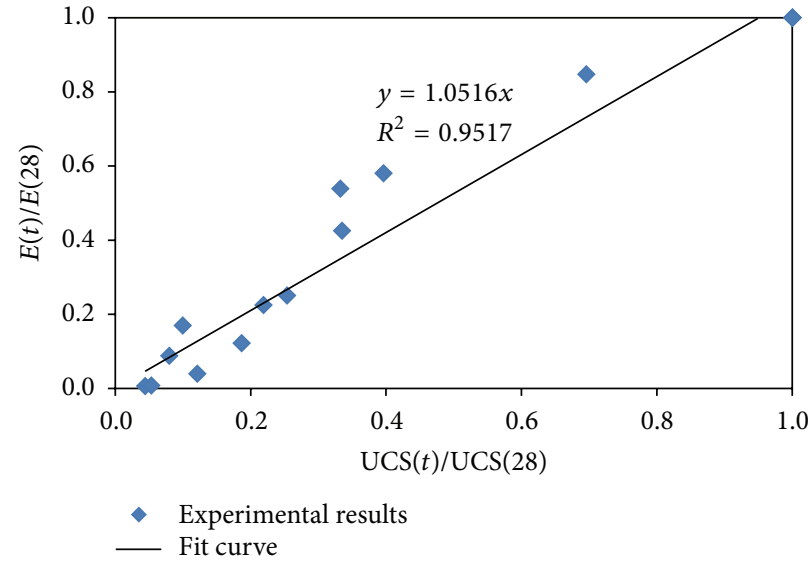

(b)

FIGURE 8: Relationship between $E(t) / E(28)$ and UCS $(t) / \mathrm{UCS}(28)$ : (a) evolution of $E(t) / E(28)$ with UCS $(t) / \mathrm{UCS}(28)$ at different initial temperatures and (b) the fit curve for $E(t) / E(28)$ and $\mathrm{UCS}(t) / \mathrm{UCS}(28)$.

in concrete; that is, the ultimate degree of binder hydration may never reach the value of 1 [18]. However, high $w / c$ ratios (5-15) are usually employed in the application of CPB operation [19]. Therefore, the full hydration of the binder can be expected to occur and leads to an ultimate degree of binder hydration of 1 . Thus, in (9), when $w / c<6.258$, the equation is valid; if $w / c>6.258, \alpha_{u}=1$ [19]. Hence, in the present study, the ultimate degree of hydration should be 1 because of the relatively high $w / c(7.6)$.

According to (6) and (7) and the recommended parameters of these two equations [14], the evolution of the degree of hydration with curing age for $\mathrm{CPB}$ at different initial temperatures can be obtained and is presented in Figure 9. This figure shows that the degree of hydration of CPB samples is significantly affected by its initial backfill temperature.
To investigate the effect of the degree of hydration on $E$ of $\mathrm{CPB}$, the following expression is used [20]:

$$
\frac{E(\alpha)}{E(\alpha=1)}=\left(\frac{\alpha(t)-\alpha_{0}}{1-\alpha_{0}}\right)^{b}
$$

where $E(\alpha)$ is the modulus of elasticity at the hydration degree of $\alpha, E(\alpha=1)$ is the modulus of elasticity at the hydration degree of $1, \alpha(t)$ is the hydration degree at the curing time $t$, and $\alpha_{0}$ and $b$ are parameters.

According to (9), $E(\alpha)$ can be expressed as a function of the degree of hydration $\alpha(t)$ :

$$
E(\alpha)=\frac{E(\alpha=1)}{\left(1-\alpha_{0}\right)^{b}}\left(\alpha(t)-\alpha_{0}\right)^{b}
$$




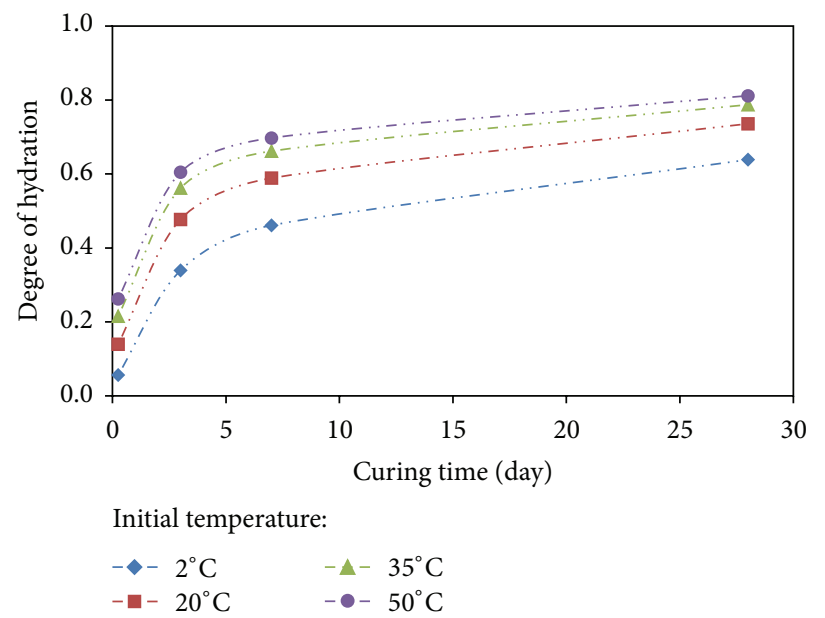

FIGURE 9: Effect of curing time on the evolution of the calculated degree of hydration at various initial temperatures.

The evolution of modulus of elasticity with degree of hydration at various initial temperatures is given in Figure 10(a). It can be observed from this figure that the modulus of elasticity increased with increase in degree of hydration. This is because the increase of hydration degree can result in more hydration products, thus leading to a higher strength. A higher strength leads to a higher elastic modulus which has been discussed in detail in Section 3.3. It also should be noted that the increase of elastic modulus with degree of hydration is very slow when it is small but accelerated if the degree of hydration is above 0.4 . This is also due to the fact that the increase of UCS accelerated as the degree of hydration is above 0.4 , which is shown as Figure 10(b).

By using $E$ modeled in (10), the scatter plot of the experimentally determined versus predicated trend line is shown in Figure 10(c). Figure 10(c) shows the relationship between $E$ and degree of hydration insignificantly affected by the initial temperature. This figure indicates that the model of (10) accurately predicts the measured results. The modulus of elasticity from the known degree of hydration is predicted, as shown in the following equation:

$$
E(\alpha)=156.216(\alpha(t)-0.056)^{2.723}
$$

The result in (11) has a significant difference compared with $b$ of concrete (recommended as 0.26-0.62) [20]. This result indicates that $\mathrm{CPB}$ is different from the concrete and the results of the concrete research cannot be directly used in the CPB design.

Moreover, the ultimate $E(E(\alpha=1))$ of $\mathrm{CPB}$ in this study can be predicted as $133.529 \mathrm{MPa}$ on the basis of (10) and (11). The predication value of $E(\alpha=1)$ is close to the average $E$ of curing age of 150 days in a column experiment that featured $E$ value of $120 \mathrm{MPa}$ at the top of the column and $170 \mathrm{MPa}$ in the middle and bottom of the column (average $E$ value of $145 \mathrm{MPa}$ ) [1]. This column experiment employed similar materials and material ratio (including STs, binder content (4.5\%), and the $w / c(7.6))$ as the present study.

\section{Conclusions}

This study has provided information that can help understand the initial temperature dependence of deformation behavior in CPB. The main conclusions derived from this study are summarized as follows:

(1) The stress-strain relations as a function of initial temperature were obtained. For the same curing age, the linear part of the stress-strain curve for high initial temperature $\mathrm{CPB}$ is steeper than that for low initial temperature CPB. Furthermore, the descending branch shows a sharp reduction with increasing initial temperature.

(2) $E$ of $\mathrm{CPB}$ increases at a high initial temperature and advanced curing age. However, as the curing age increases to 28 days, first the increase $\left(2^{\circ} \mathrm{C}-35^{\circ} \mathrm{C}\right)$ and then decrease $\left(35^{\circ} \mathrm{C}-50^{\circ} \mathrm{C}\right)$ of $E$ values can be observed with increasing initial temperature.

(3) $E$ as a function of the uniaxial compressive strength of CPB is not significantly affected by initial temperature. Moreover, the ratio of $E(t) / E(28 \mathrm{~d})$ is almost equal to the ratio of $\operatorname{UCS}(t) / \mathrm{UCS}(28 \mathrm{~d})$. The effect of the initial temperature is minor.

(4) The strong relationship between $E$ and degree of hydration was investigated under the small effect of initial temperature. The equation predicting $E$ from the known degree of hydration was obtained. The ultimate $E$ predicted by this equation is in good agreement with the result of curing age of 150 days conducted by other studies.

\section{Competing Interests}

The authors declare that there are no competing interests regarding the publication of this paper. 


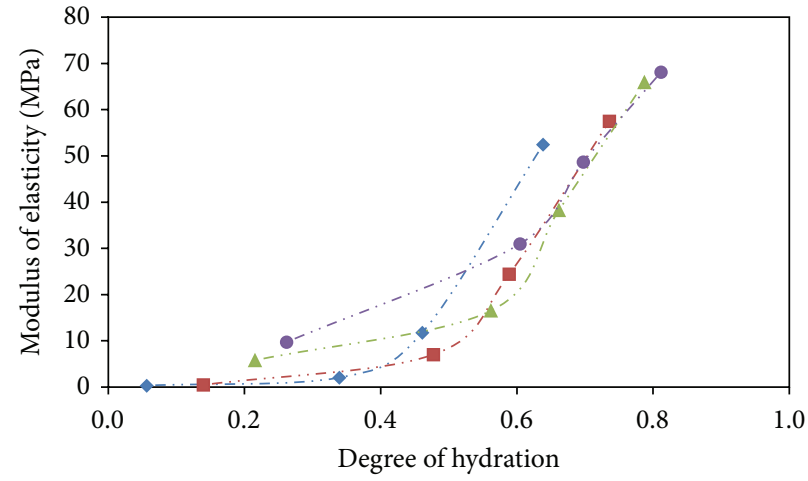

Initial temperature:

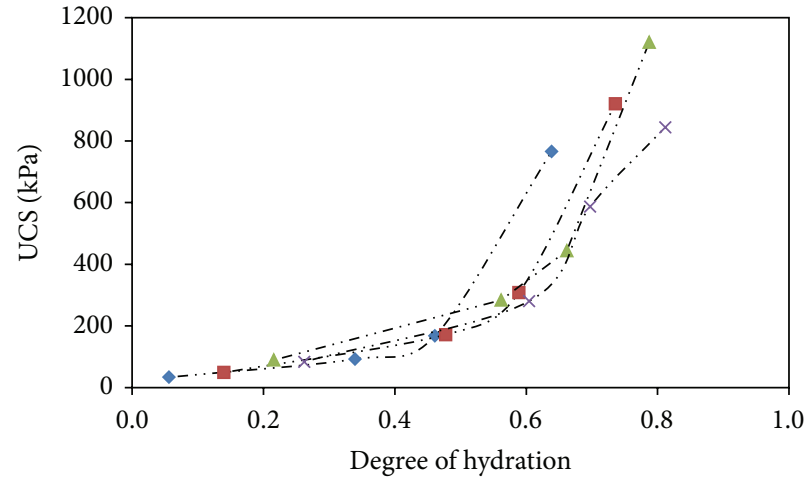

Initial temperature:

$\begin{array}{ll}--2{ }^{\circ} \mathrm{C} & --35^{\circ} \mathrm{C} \\ --20^{\circ} \mathrm{C} & -\rtimes-50^{\circ} \mathrm{C}\end{array}$

(b)

(a)

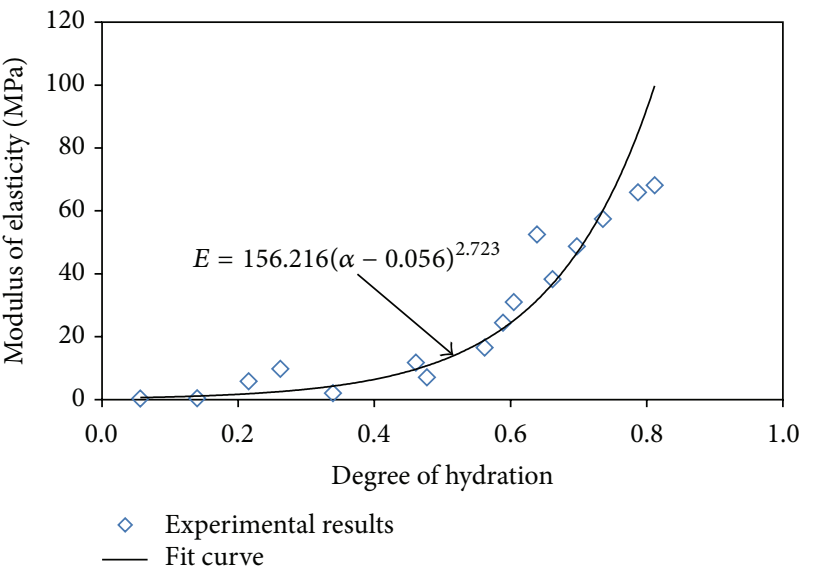

(c)

FIGURE 10: Effect of initial temperature on the relationship between $E$, UCS, and degree of hydration: (a) relationship between $E$ and degree of hydration, (b) relationship between UCS and degree of hydration, and (c) the scatter plot of the experimentally determined versus predicated trend line for $E$ and degree of hydration.

\section{Acknowledgments}

This research was funded by Beijing Municipal Science and Technology Commission (no. Z161100001216002), the National Key Technologies R\&D Program for the 12th Five-Year Plan (nos. 2012BAB08B02, 2013BAB02B05), the National Natural Science Foundation of China (nos. 51574013, 51374034), and the University of Science and Technology Beijing. Also, the authors thank Dr. Hongjiang Wang and Fei Jin for their help in refining the paper.

\section{References}

[1] A. Ghirian and M. Fall, "Coupled thermo-hydro-mechanicalchemical behaviour of cemented paste backfill in column experiments: part II: mechanical, chemical and microstructural processes and characteristics," Engineering Geology, vol. 170, pp. 11-23, 2014.

[2] J. Cayouette, "Optimization of the paste backfill plant of Louvicourt mine," CIM Bulletin, vol. 96, no. 1075, pp. 51-57, 2003.
[3] T. Belem and M. Benzaazoua, "Design and application of underground mine paste backfill technology," Geotechnical and Geological Engineering, vol. 26, no. 2, pp. 147-174, 2008.

[4] M. Fall, T. Belem, S. Samb, and M. Benzaazoua, "Experimental characterization of the stress-strain behaviour of cemented paste backfill in compression," Journal of Materials Science, vol. 42, no. 11, pp. 3914-3922, 2007.

[5] J. Myers, "Use of high strength/high performance concrete in America: a code and application perspective," in Proceedings of the 8th International Symposium on Utilization of HighStrength and High-Performance Concrete, pp. 13-22, Tokyo, Japan, October 2008.

[6] M. Fall, J. C. Célestin, M. Pokharel, and M. Touré, "A contribution to understanding the effects of curing temperature on the mechanical properties of mine cemented tailings backfill," Engineering Geology, vol. 114, no. 3-4, pp. 397-413, 2010.

[7] A. M. Neville, "Aggregate bond and modulus of elasticity of concrete," ACI Materials Journal, vol. 94, no. 1, pp. 71-74, 1997.

[8] T. W. Bremner and T. A. Holm, "Elastic compatibility and the behavior of concrete," Journal of the American Concrete Institute, vol. 83, no. 2, pp. 244-250, 1986. 
[9] O. Sengul, C. Tasdemir, and M. A. Tasdemir, "Influence of aggregate type on mechanical behavior of normal- and highstrength concretes," ACI Materials Journal, vol. 99, no. 6, pp. 528-533, 2002.

[10] J. Wongpa, K. Kiattikomol, C. Jaturapitakkul, and P. Chindaprasirt, "Compressive strength, modulus of elasticity, and water permeability of inorganic polymer concrete," Materials \& Design, vol. 31, no. 10, pp. 4748-4754, 2010.

[11] H. Yıldırım and O. Sengul, "Modulus of elasticity of substandard and normal concretes," Construction and Building Materials, vol. 25, no. 4, pp. 1645-1652, 2011.

[12] M. Nematzadeh and M. Naghipour, "Compressive strength and modulus of elasticity of freshly compressed concrete," Construction and Building Materials, vol. 34, pp. 476-485, 2012.

[13] I. Pane and W. Hansen, "Concrete hydration and mechanical properties under nonisothermal conditions," ACI Materials Journal, vol. 99, no. 6, pp. 534-542, 2002.

[14] A. K. Schindler, "Effect of temperature on hydration of cementitious materials," ACI Materials Journal, vol. 101, no. 1, pp. 72-81, 2004.

[15] T. C. Hansen, "Physical structure of hardened cement paste. A classical approach," Materials and Structures, vol. 19, no. 6, pp. 423-436, 1986.

[16] R. Mills, "Factors influencing cessation of hydration in water cured cement pastes," Highway Research Board Special Report 90, 1966.

[17] K. O. Kjellsen, R. J. Detwiler, and O. E. Gjørv, "Development of microstructures in plain cement pastes hydrated at different temperatures," Cement and Concrete Research, vol. 21, no. 1, pp. 179-189, 1991.

[18] A. K. Schindler and K. J. Folliard, "Influence of supplementary cementing materials on the heat of hydration of concrete," in Proceedings of the Advances in Cement and Concrete IX Conference, Colorado, pp. 10-14, 2004.

[19] D. Wu, M. Fall, and S.-J. Cai, "Coupled modeling of temperature distribution and evolution in cemented tailings backfill structures that contain mineral admixtures," Geotechnical and Geological Engineering, vol. 30, no. 4, pp. 935-961, 2012.

[20] G. De Schutter and L. Taerwe, "Degree of hydration-based description of mechanical properties of early age concrete," Materials and Structures, vol. 29, no. 190, pp. 335-344, 1996. 

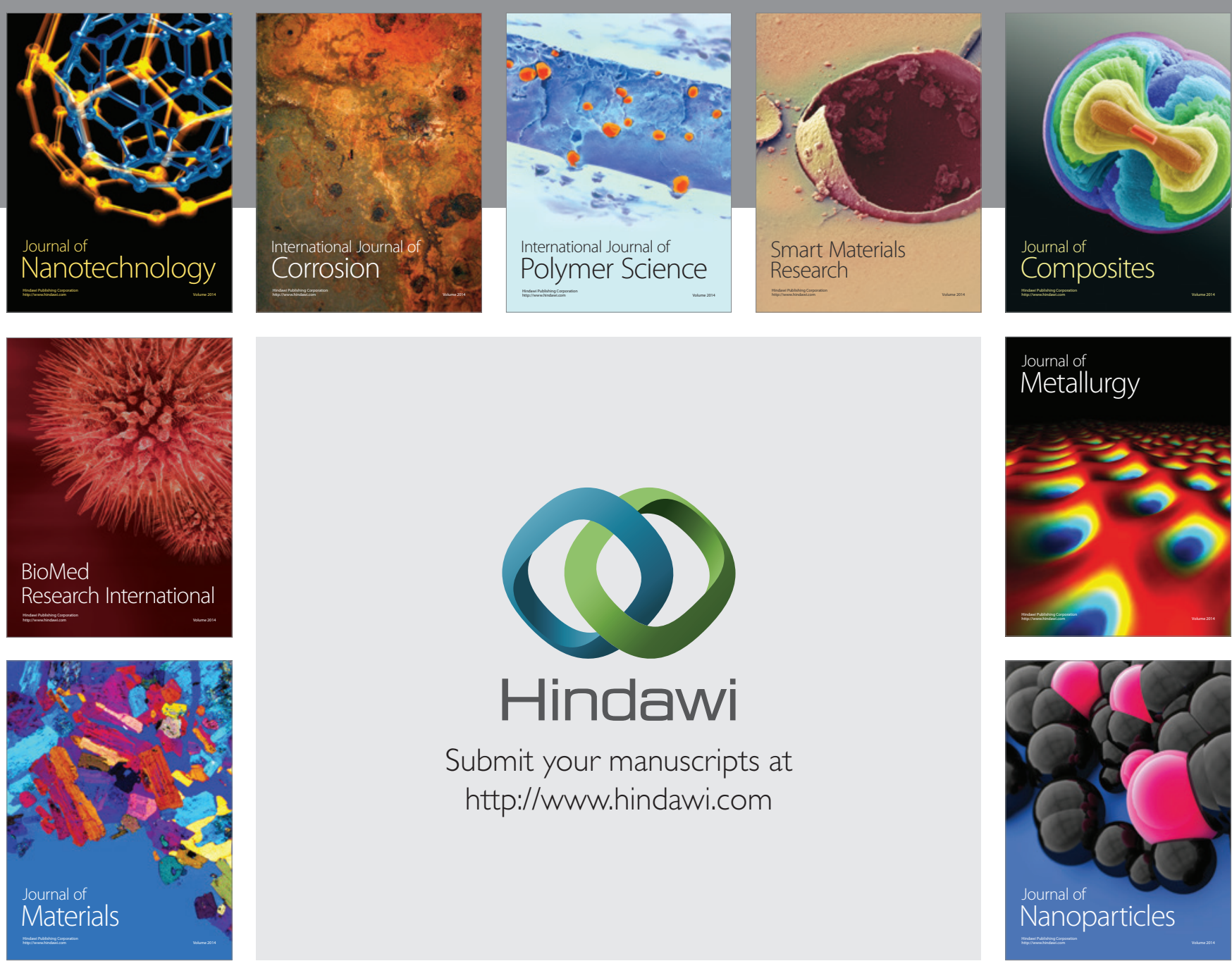

\section{Hindawi}

Submit your manuscripts at

http://www.hindawi.com

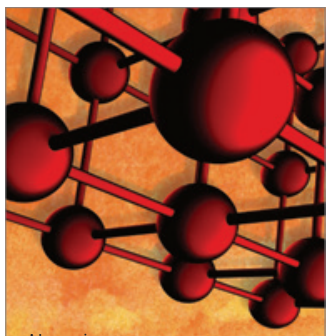

Materials Science and Engineering
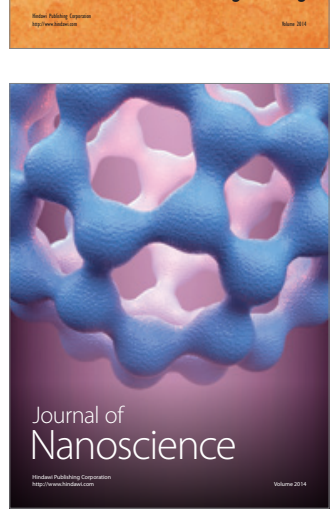
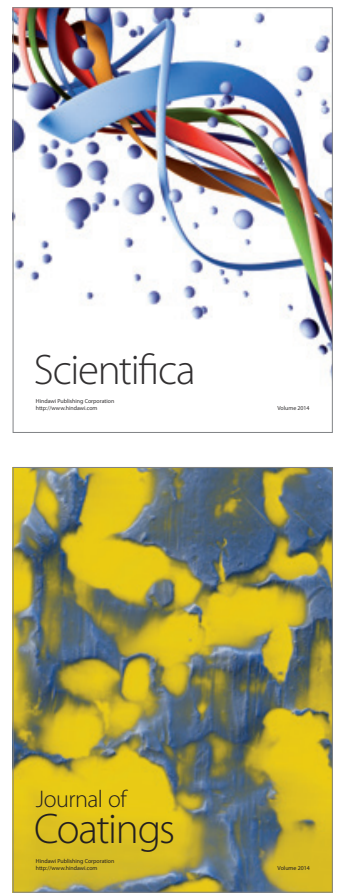
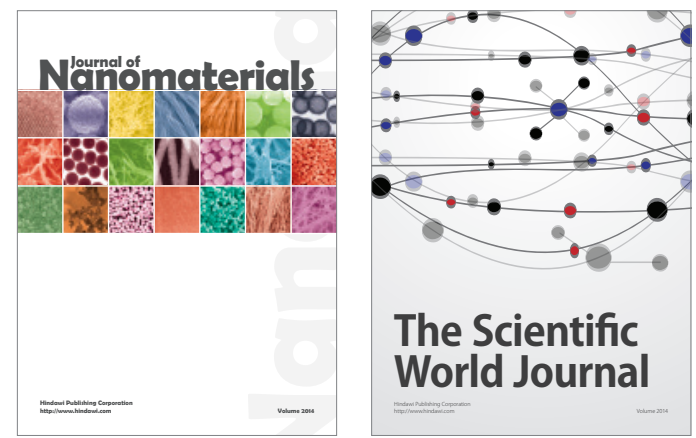

The Scientific World Journal
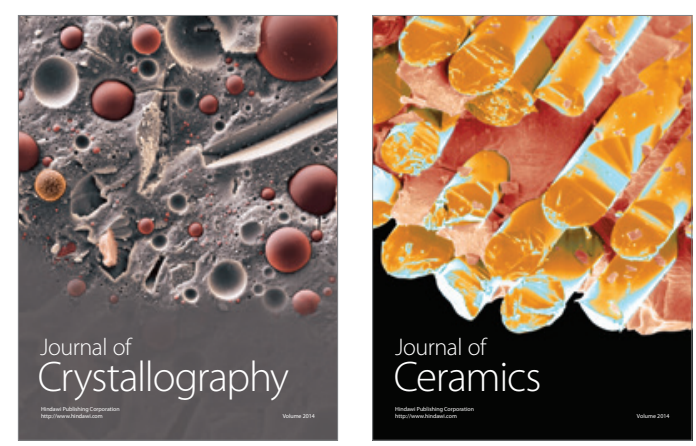
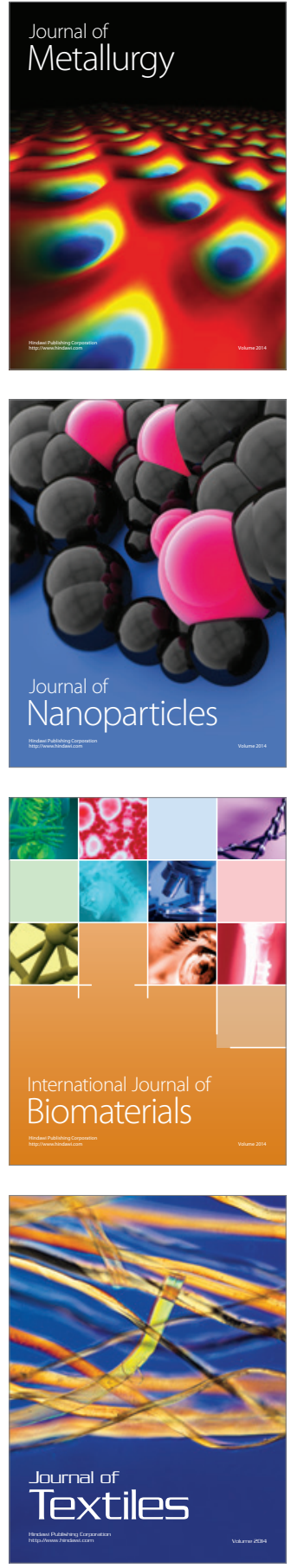